\title{
Alternative preparation of size-controlled thiol-capped gold colloids
}

\author{
Martin Makosch • Václav Bumbálek • Jacinto Sá • \\ Jeroen A. van Bokhoven \\ Published online: 7 June 2013 \\ (C) The Author(s) 2013. This article is published with open access at SpringerLink.com
}

\begin{abstract}
Colloidal nanoparticles find application in chemistry, biology, and life science. We report an alternative preparation method for thiol-capped gold colloids by leaching of premade particles on a support. Via this method, monodispersed particles in the size of 2 to $2.5 \mathrm{~nm}$ can be obtained whereas the occurrence of bigger particles is restricted.
\end{abstract}

Keywords Gold · Colloid · Nanoparticle · Thiol-capped

An increasing interest in colloidal nanoparticles developed over the past years as an ever-growing number of applications in chemistry, biology, and life science emerged [1]. In biology and life science, these colloids are used for labeling [2], (drug) delivery [3], heating [4], and sensing [5] whereas supported [6] or unsupported [7] nanoparticles in chemistry are used especially in the field of catalysis. Although numerous preparation methods for colloidal nanoparticles exist [8-10], scientists still look for alternative routes as the demand for small monodispersed nanoparticles in solution is high. The challenge in the preparation of colloid gold nanoparticles is the size control especially in the regime below $5 \mathrm{~nm}$ as gold tends to sinter easily. Gold colloids are typically synthesized through reduction of a gold precursor in solution. We propose an alternative preparation method which yields monodispersed organic thiol-capped gold colloids in the size of 2 to $2.5 \mathrm{~nm}$ and prevents the occurrence of nanoparticles bigger than $5 \mathrm{~nm}$.

Electronic supplementary material The online version of this article (doi:10.1007/s13404-013-0093-x) contains supplementary material, which is available to authorized users.

M. Makosch $(\bowtie) \cdot$ V. Bumbálek $\cdot$ J. A. van Bokhoven Institute for Chemical and Bioengineering, ETH Zurich, Wolfgang-Pauli Strasse,

8093 Zurich, Switzerland

e-mail: m.mkosch@gmx.net

J. Sá • J. A. van Bokhoven

Paul Scherrer Institute (PSI), Villigen, Switzerland
The method is based on the leaching of premade particles that are attached to a support. Because of the ability to control the gold particle size in supported gold [10], the method provides new opportunities to synthesize gold colloids of well-defined size.

The gold colloids were obtained from $\mathrm{Au} / \mathrm{Al}_{2} \mathrm{O}_{3}$ colloid precursors which were prepared by a deposition precipitation with urea method according to [11]. The $\mathrm{Au} / \mathrm{Al}_{2} \mathrm{O}_{3}$ colloid precursor and the colloid were characterized by transmission electron microscopy (TEM), atomic absorption spectroscopy, and high-energy resolution fluorescence-detected X-ray absorption spectroscopy (HERFD XANES). All experimental details of $\mathrm{Au} / \mathrm{Al}_{2} \mathrm{O}_{3}$ colloid precursor synthesis, colloid preparation, and characterization can be found in the supplementary information. In short, a suspension of the $\mathrm{Al}_{2} \mathrm{O}_{3}$ support, urea, and an appropriate amount of $\mathrm{HAuCl}_{4} \cdot 3 \mathrm{H}_{2} \mathrm{O}$ in water was prepared and stirred at $80{ }^{\circ} \mathrm{C}$ for $16 \mathrm{~h}$ under the exclusion of light. The powder was filtered, washed three times with water, and dried in vacuum overnight. After pretreatment in a flow of $5 \% \mathrm{H}_{2} / \mathrm{He}$ at $300{ }^{\circ} \mathrm{C}$, the $\mathrm{Au} / \mathrm{Al}_{2} \mathrm{O}_{3}$ precursor was mixed with the corresponding organic thiol in degassed (with $\mathrm{N}_{2}$ ) ethanol at a molar $\mathrm{Au} /$ thiol ratio of $1 / 20$ for $16 \mathrm{~h}$. After that, the catalyst was filtered, washed three times with $\mathrm{EtOH}$, and dried in vacuum overnight. We refer to the 1-dodecanethiol-capped $\mathrm{Au} / \mathrm{Al}_{2} \mathrm{O}_{3}$ colloid precursor as " $\mathrm{Au}_{\mathrm{C} 12} / \mathrm{Al}_{2} \mathrm{O}_{3}$ " in the following. The gold colloid was obtained by heating $\mathrm{Au}_{\mathrm{C} 12} / \mathrm{Al}_{2} \mathrm{O}_{3}$ in toluene at the corresponding temperature. We refer to the 1dodecanethiol-capped gold colloid as " $\mathrm{Au}_{\mathrm{C} 12}$ colloid" in the following.

The transition of the gold nanoparticles from the $\mathrm{Al}_{2} \mathrm{O}_{3}$ support to the liquid phase is visualized in Fig. 1. Figure 1 shows a characteristic TEM picture of $\mathrm{Au}_{\mathrm{C} 12} / \mathrm{Al}_{2} \mathrm{O}_{3}$ before and the $\mathrm{Au}_{\mathrm{C} 12} / \mathrm{Al}_{2} \mathrm{O}_{3}$ and the liquid toluene phase after heating in toluene at $80{ }^{\circ} \mathrm{C}$.

Before heating in toluene, the thiol-capped $\mathrm{Au}$ nanoparticles were monodispersed and widely distributed on the $\mathrm{Al}_{2} \mathrm{O}_{3}$ support with a mean particle size of $2.8 \mathrm{~nm}$. 


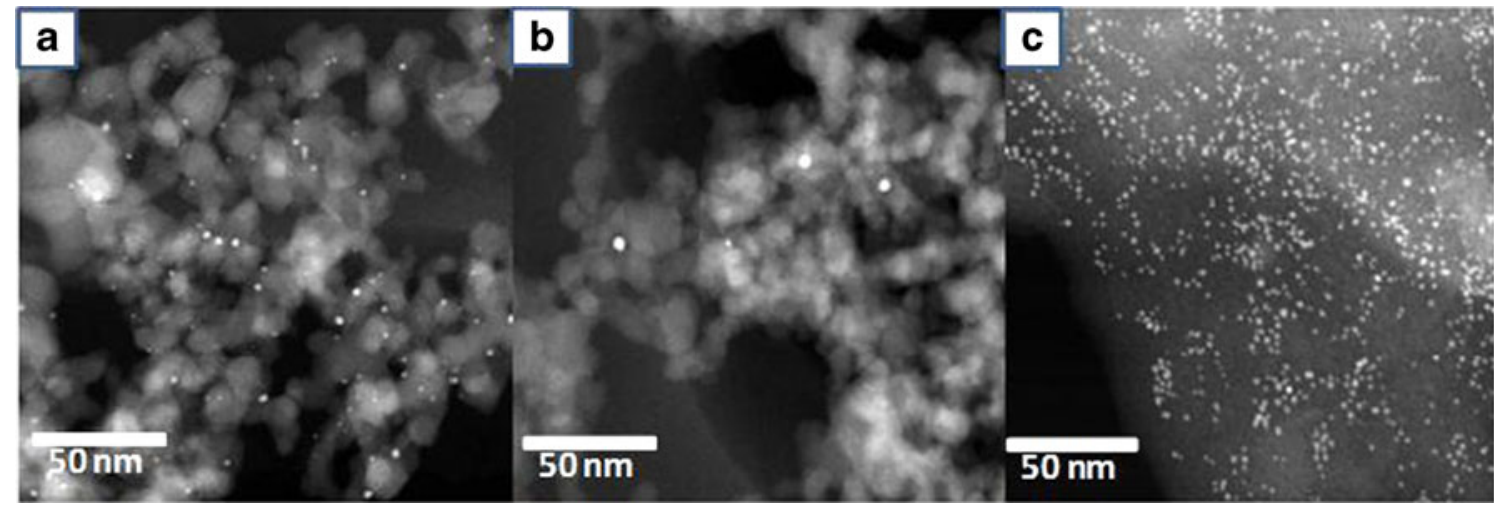

Fig. 1 Characteristic TEM picture of $\mathrm{Au}_{\mathrm{C} 12} / \mathrm{Al}_{2} \mathrm{O}_{3}$ before (a) and after (b) heating at $80{ }^{\circ} \mathrm{C}$ in toluene and the liquid phase after heating at $80{ }^{\circ} \mathrm{C}$

After heating, the $\mathrm{Al}_{2} \mathrm{O}_{3}$ support showed only residual big nanoparticles $(>5 \mathrm{~nm})$ on the surface of the $\mathrm{Al}_{2} \mathrm{O}_{3}$ support whereas all smaller sized nanoparticles had disappeared. These particles were found in the toluene phase which turned from colorless to dark red, because of the gold colloid. The mean particles size was $2.7 \mathrm{~nm}$ suggesting, combined with the HERFD XANES data (supplementary information), that the gold nanoparticles leached into the liquid toluene phase as a whole. We investigated the effect of temperature on the colloid. Figure 2 shows the particle size distribution (left) and a characteristic TEM picture (right) of the $\mathrm{Au}_{\mathrm{C} 12}$ colloid after heating at $80^{\circ} \mathrm{C}$ (a) and $100^{\circ} \mathrm{C}$ (b) in toluene.
The particle size distribution obtained by heating the $\mathrm{Au}_{\mathrm{C} 12} / \mathrm{Al}_{2} \mathrm{O}_{3}$ catalyst in toluene at $80{ }^{\circ} \mathrm{C}$ (a) resulted in a Gaussian shape with a maximum at $2.2 \mathrm{~nm}$. The characteristic TEM picture shows spherical monodispersed gold nanoparticles of the same size. Heating the $\mathrm{Au}_{\mathrm{C} 12} / \mathrm{Al}_{2} \mathrm{O}_{3}$ at $100{ }^{\circ} \mathrm{C}$ (b) in toluene resulted also in spherical $\mathrm{Au}_{\mathrm{C} 12}$ nanoparticles with a Gaussian particle size distribution, but much narrower compared to (a). The maximum was located at $1.8 \mathrm{~nm}$. Additionally to the temperature effect, we investigated the effect of the molar $\mathrm{Au} / \mathrm{S}$ ratio during the $\mathrm{Au}_{\mathrm{C} 12} / \mathrm{Al}_{2} \mathrm{O}_{3}$ treatment and subsequent heating at $80{ }^{\circ} \mathrm{C}$ on the resulting $\mathrm{Au}_{\mathrm{C} 12}$ colloid. Table 1 summarizes the effect
Fig. 2 Particle size distribution (left) and characteristic TEM image (right) of the $\mathrm{Au}_{\mathrm{C} 12}$ colloid after heating at $\mathbf{a} 80^{\circ} \mathrm{C}$ and $\mathbf{b} 100{ }^{\circ} \mathrm{C}$
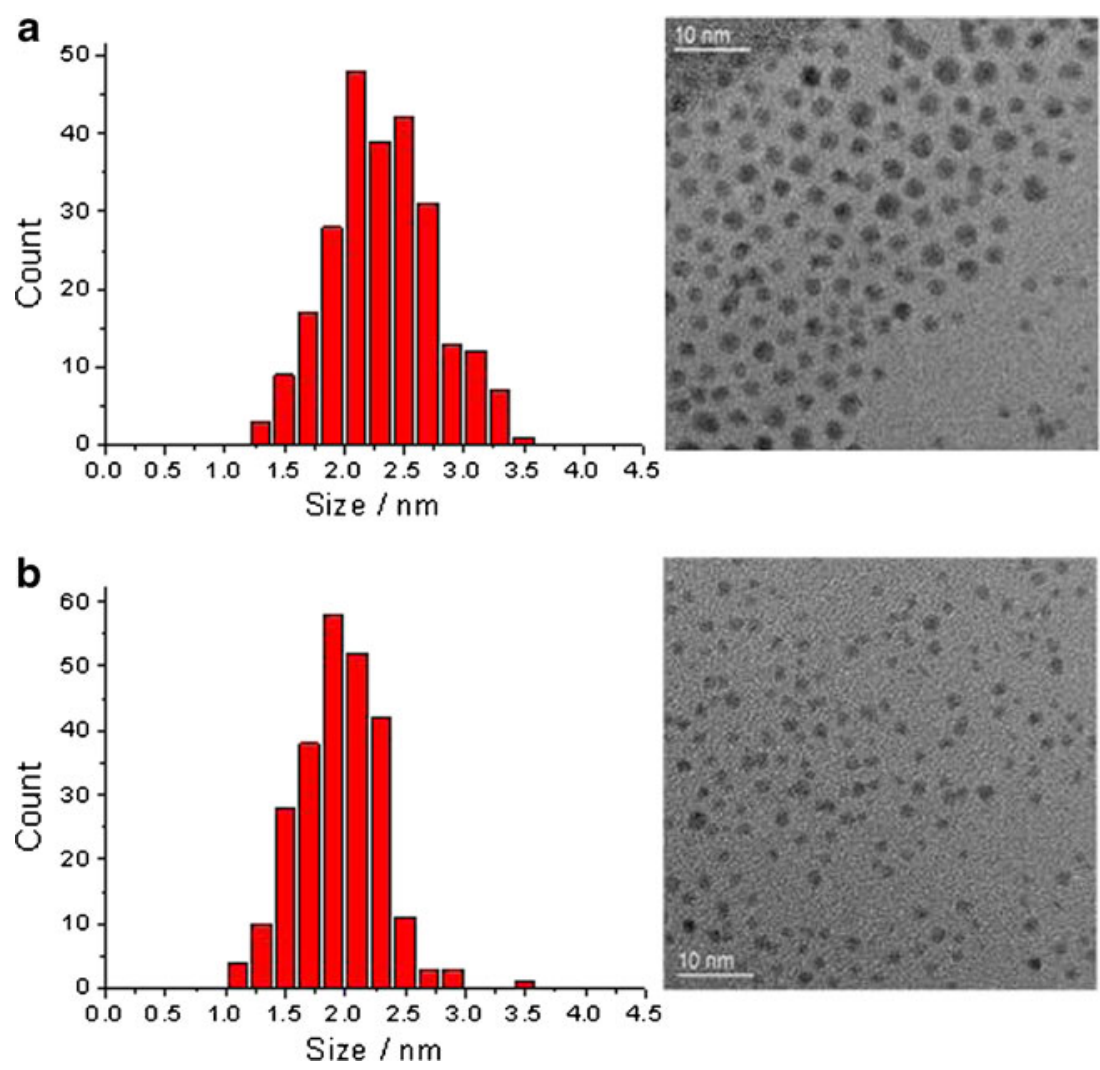
Table 1 Dependence of $\mathrm{Au} / \mathrm{S}$ ratio on $\mathrm{Au}$ colloid yield for the $\mathrm{Au}_{\mathrm{C} 12}$ colloid after heating the $\mathrm{Au}_{\mathrm{C} 12} / \mathrm{Al}_{2} \mathrm{O}_{3}$ colloid precursor in toluene at $80{ }^{\circ} \mathrm{C}$

\begin{tabular}{ll}
\hline Molar Au/S ratio & Au colloid yield (\%) \\
\hline $1: 20$ & 66.9 \\
$10: 1$ & 33.2 \\
$25: 1$ & 6.2 \\
$50: 1$ & - \\
$75: 1$ & - \\
\hline
\end{tabular}

Table 2 Dependence of organic thiol on Au colloid yield after heating in toluene at $80{ }^{\circ} \mathrm{C}$

\begin{tabular}{lc}
\hline Thiol & Au colloid yield (\%) \\
\hline 1-Octadecanethiol & 78.5 \\
1-Dodecanethiol & 66.9 \\
1-Propanethiol & 62.5 \\
1,6-Hexanedithiol & 11.5 \\
1-Thioglycerol & 7.3 \\
\hline
\end{tabular}

Table 3 Dependence of solvent on $\mathrm{Au}$ colloid for the $\mathrm{Au}_{\mathrm{C} 12}$ colloid yield after heating in toluene at $80^{\circ} \mathrm{C}$

\begin{tabular}{lc}
\hline Solvent & Au colloid yield (\%) \\
\hline$n$-Hexane & 74.6 \\
Toluene & 66.9 \\
Ethanol & 24.5 \\
Water & 23.4 \\
\hline
\end{tabular}

on the yield of $\mathrm{Au}_{\mathrm{C} 12}$ colloid for different molar $\mathrm{Au} / \mathrm{S}$ ratios of the $\mathrm{Au}_{\mathrm{C} 12} / \mathrm{Al}_{2} \mathrm{O}_{3}$ colloid precursor.

Whereas no effect on the particle size was observed, we found that the gold colloid yield in toluene strongly depended on the molar $\mathrm{Au} / \mathrm{S}$ ratio during the preparation of the $\mathrm{Au}_{\mathrm{C} 12} / \mathrm{Al}_{2} \mathrm{O}_{3}$ colloid precursors. Whereas no leaching was observed for $\mathrm{Au} / \mathrm{S}$ ratios of $75: 1$ and 50:1, gold nanoparticles were transferred to the liquid phase starting at ratios of 25:1. Higher gold colloid yields could be achieved via the application of different organic thiols, without affecting the size (Table 2). The maximum amount of gold that could be brought into solution was almost $80 \%$, which is likely because the bigger nanoparticles remain on the $\mathrm{Al}_{2} \mathrm{O}_{3}$ support as observed in Fig. $1 \mathrm{~b}$.

In general, thiols with a similar polarity as the solvent toluene (1-propanthiol, 1-dodecanethiol, 1-octadecanethiol) yielded higher gold colloid concentration, whereas thiols with an adjacent polar group resulted in lower concentrations. Within a row of the unpolar thiols, a longer $\mathrm{CH}_{3}\left(\mathrm{C}_{n} \mathrm{H}_{2 n}\right)$ chain yielded a higher gold colloid concentration with a maximum of $78.5 \%$ observed for 1-octadecanethiol in toluene. The same trend was observed within the polar thiols. A similar tendency was observed for the preparation of the $\mathrm{Au}_{\mathrm{C} 12}$ colloid in different solvents (Table 3).

The gold colloid yield strongly depended on the solvent used during preparation: the more polar the solvent and thus the more interaction of the $\mathrm{CH}_{3}\left(\mathrm{CH}_{2}\right)_{12}$ chain with the solvent, the higher the gold colloid yield. The maximum $\mathrm{Au}_{\mathrm{C} 12}$ colloid yield was obtained in the most unpolar solvent, $n$-hexane, whereas as much as $50 \%$ less was observed in the most polar solvent, water. According to these observations, we propose a model for the fabrication of the size-controlled thiol-capped gold nanoparticles as depicted in Scheme 1.
Scheme 1 Schematic representation for the formation of thiol-capped gold nanoparticles

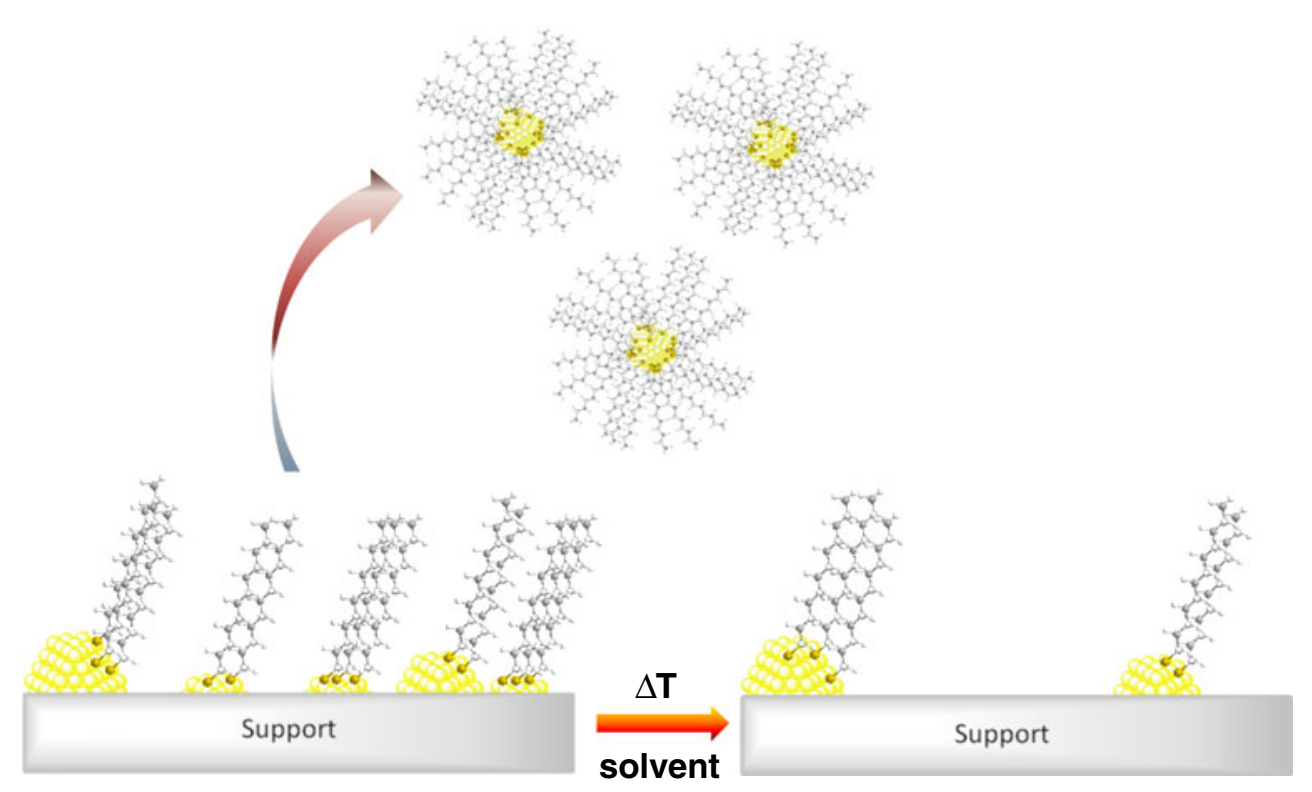


Due to the interaction of the long $\mathrm{CH}_{3}\left(\mathrm{C}_{n} \mathrm{H}_{2 n}\right)$ chains with the solvent, the organic thiol-capped nanoparticles are transferred to the liquid phase in the same structure as they had on the support. The better the interaction between the organic thiols and the solvent, the higher the Au colloid yield, whereas this interaction is not strong enough to rip of particles bigger than $5 \mathrm{~nm}$.

To summarize, we showed that monodispersed thiolcapped gold colloids in the range of 2 to $2.5 \mathrm{~nm}$ can be synthesized by initial treatment of $\mathrm{Au} / \mathrm{Al}_{2} \mathrm{O}_{3}$ colloid precursors with organic thiols and subsequent heating in a solvent. Size control during preparation is given as particles bigger than $5 \mathrm{~nm}$ remain on the $\mathrm{Al}_{2} \mathrm{O}_{3}$ surface whereas all smaller sizes are transferred to the liquid phase. Variation of colloid precursor treatment and extraction temperature enables fine tuning of particle size whereas the yield of the gold colloid can be maximized via the right combination of organic thiol and solvent. This new route opens a new horizon for the production of colloidal particles in the size range below $5 \mathrm{~nm}$.
Open Access This article is distributed under the terms of the Creative Commons Attribution License which permits any use, distribution, and reproduction in any medium, provided the original author(s) and the source are credited.

\section{References}

1. Sperling RA, Rivera Gil P, Zhang F, Zanella M, Parak WJ (2008) Chem Soc Rev 37:1896

2. Agasti SS, Rana S, Park M-H, Kim CK, You C-C, Rotello VM (2010) Adv Drug Deliver Rev 62:316

3. Duncan B, Kim C, Rotello VMJ (2010) Control Release 148:122

4. Wilson BC (2010) Handbook of Photonics for Biomedical Science. CRC Press, Boca Raton

5. Dykman L, Khlebtsov N (2012) Chem Soc Rev 41:2256

6. Jia C-J, Liu Y, Bongard H, Schüth FJ (2010) Am Chem Soc $132: 1520$

7. Liang X, Wang Z-j, Liu C-j (2010) Nanoscale Res. Let 5:124

8. Xu B, Song RG, Wang C (2011) Adv Mater Res 415-417:648

9. Liu S, Chen G, Prasad PN, Swihart MT (2011) Chem Mater 23:4098

10. Bond GC, Louis C, Thompson DT (2006) Catalysis by gold. Imperial College Press, London

11. Hugon A, Delannoy L, Louis C (2008) Gold Bull 41:127 